\title{
Influence of Regulation on Chinese Tobacco Industry from the Perspective of Game Theory
}

\author{
Shen Shen* \\ Economic Department of Teaching and Research \\ Party School of the Yunnan Provincial Committee of C.P.C \\ \&School of Economics \\ Yunnan University of Finance and Economics \\ Kunming, China \\ leon198633@sina.com
}

\author{
Jiang Min \\ Office of Academic Research \\ Party School of the Yunnan Provincial Committee of C.P.C \\ Kunming, China
}

\begin{abstract}
Tobacco industry enjoys monopoly, and the tobacco products share the characteristics of high margin, high revenue as well as addictiveness and harmfulness. The Chinese tobacco industry has been in a system of state monopoly, which, on one side, ensures stable development of the tobacco industry, and on the other side, causes negative impacts on the tobacco industry market structure and market behavior. The paper focuses on the research of causes and influences of the Chinese tobacco regulation from the perspective of game theory, analyzes the existing problems in the tobacco industry, puts forward relevant policy recommendations in order to improve relevant regulation and measures and finalizes that combining market and government control is the most conducive way to the development of the tobacco industry.
\end{abstract}

Keywords—Tobacco Industry; Regulation; Game Theory

\section{RESEARCH BACKGROUND}

Tobacco industry is an important economic source of national and local fiscal revenues. It mainly includes planting, processing and selling of tobacco. Regulation refers to the state's intervention in the name of economic management. It also refers to various actions taken by the government to control enterprises' price, sales and production decisions. The government makes public announcement of these actions to aim at stopping the private decision which doesn't fully value "social interests". ${ }^{1}$ After China's joining WTO and signing the Framework Convention on tobacco control, the Chinese tobacco industry has been facing great opportunities and challenges. Therefore, it is urgent to improve the regulation system to promote its healthy development. The paper analyzes the regulation policy of Chinese tobacco industry, compares with the situation of the United States, and does some research on the reason, effect and problem of the existing regulation by use of Industrial Economics, Circulation Economics and Game Theory in order to perfect the regulation policy and promote the development of Chinese tobacco

* Corresponding author. This paper is funded by "Research on Farmers' Producing Behaviors under the Regulation of Yunnan Tobacco" (2017FD125) \& "Research on Circulation Competitiveness of Yunnan Tobacco Enterprise" (2016D01).

${ }^{1}$ John Eatwell etc. compiles, "The New Palgrave Dictionary of Economics" (fourth volumes), Economic Science Press, 1996, 135-136 pages. industry. Among many regulation theories, Zi CaoYi (1987) argues that the regulation in the usual sense refers to the restrictions on the activities carried by individuals and economic entities according to certain regulation, the former of which constitutes specific society and the latter of which constitutes economics. The main theories for tobacco industry regulation are the "Rational Addiction Theory" by Becker and Murphy (1998). It puts forward the "cold turkey" policy rather than by government regulation to terminate the addiction process. The theory emphasizes to use taxation to regulate tobacco, which is a kind of economic instrument by the government for macroeconomic control, i.e. to maintain the stable development of the tobacco market by using the "visible hand". Domestically, Luo Meijuan (2004) argues that the government regulation of the tobacco industry is reflected by social regulation, market structure regulation, entry regulation and quality regulation etc. Such regulation not only distorts the operational behavior of the tobacco industry but eventually led to the limited market competition pattern under the protection of regional interests.

\section{ReAsons FOR the Regulation of Chinese ToBACCO INDUSTRY}

Tobacco industry is a special industry, which shares the industrial characteristics of monopoly and scale economy etc., and tobacco products are addictive and dangerous chronic drugs. The tobacco industry is also an important source of national taxation. Most countries in the world have relaxed or even abolished the government regulation of tobacco industry. China is one of the few countries insisting on holding tobacco monopoly system.

\section{A. Harmfulness and negative externality of tobacco industry}

The most important reason for the regulation of tobacco industry is the harm of tobacco products to the human body and the environmental pollution caused by the tobacco products, i.e. the negative externality of tobacco products. Tobacco products can be addictive and have serious damage to human organs such as heart and lung, thus needs to be controlled. Generally, the state regulates tobacco products by means of price, i.e. rising the price of tobacco products in the form of tax. Tobacco products belong to commodity of low 
elasticity of price, and He Dongmei (2003) got “-0.272” as the price elasticity for the tobacco industry in China by calculation. Tobacco consumption also brings huge social costs. According to Tao Ming's estimation (2005), the social productivity loss caused by smoking in China in 2010 was about 170.652 billion yuan (RMB). The Chinese government has launched a plan of "prohibition by taxation", which restricts production and sales by levying high taxes and restricts tobacco demand by levying high consumption tax to achieve the smoke-free purpose.

The negative externality produced in the tobacco industry is shown in the following sketch:

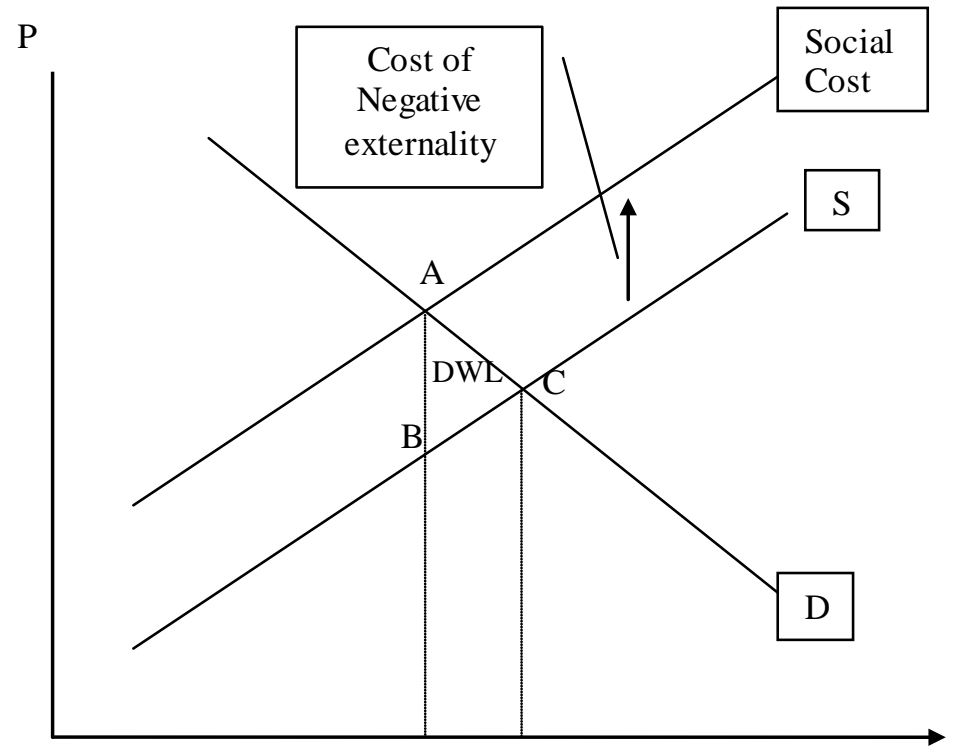

$$
\begin{array}{cc}
\text { Q of } & \text { Q of } \\
\text { Optimum } & \text { Market }
\end{array}
$$

Fig. 1. Negative Externality Sketch of Tobacco Enterprises

Therefore, the state selects tax means to pay the rise of social cost led by its negative externality and controls the related pollution. Another negative externality of the tobacco industry is expressed by the damage to the body of nonsmokers, namely, the problem of "secondhand smoke", which is mainly solved by policy measures to forbid smoking in public area as required by the "Convention": it must be strictly implemented to ensure the "second-hand smoke" to be eliminated.

\section{B. Government's Tax Dependence on Tobacco Industry}

As a high-tax industry, the tobacco industry has been a large source of fiscal revenue for the state and local governments, and takes higher and higher proportion of fiscal revenue, which accounts for more than $10 \%$ of the country's financial revenues. It becomes more obvious in local area that, taking Yunnan Province as an example, tobacco taxes generally accounts for more than $70 \%$ of the local revenue. The state established high tax rate to tobacco planting, production and sales, which, on one hand, has achieved the goal of "Smoke-Free", and on the other hand, has also accumulated funds. In this way, the state, especially the local governments, must strictly control it so as to ensure the stability of the fiscal revenues. If the regulation is released, the tax will be heavily reduced or even disappeared, which shall have negative effect on the current economic development.

\section{Historical Reasons and Actual Conditions of Chinese Economic Development}

China, since its foundation, has experienced a transition from planned economy to market economy and intervenes in the market by adhering to the country's "visible hand", so China's tobacco industry has not experienced the period of free merger and reorganization as did by the Western countries. Obviously insufficient of monopoly and economical efficiency of scale in China, tobacco industry has been in a system of state monopoly, and once the regulation is suddenly released, it will cause the fluctuation of the market and influence the development of tobacco industry. In addition, China has the world's largest population and is the largest cigarette consuming country, thus, the harm caused by smoking is also far greater, wider, more difficult to control and higher cost to take than that of other countries in the world. Considering the weak competitiveness and local separations of China's tobacco enterprises, the numerous population and smokers in China and the government as the maintainer of the national interests and as the representative of state-owned enterprises, the state hopes, through strict regulations, to improve the tobacco market entry barriers, to prevent flooding of the domestic tobacco enterprises and to prevent invasion of foreign tobacco companies of strong market competitiveness, which has the features of industrial protection, planned economy and administrative monopoly.

To sum up, as the administrator of public order, the spokesman of public interests, bearer of public construction, maintainer of the national interests and owner of state enterprises, the government hopes to centralize and manage the harmful and addictive tobacco, to obtain an important source of the national finance through the imposition of heavy taxes ("prohibition by taxation"), and to protect the developing domestic tobacco industries. Therefore, China has chosen to regulate tobacco industry, strictly implemented the national tobacco monopoly system by regulating its planting area, purchase quantity, production and consumption.

\section{ANALysis of THE EFFECT of REgulation ON Chinese TOBACCO}

By regulation of the tobacco industry, China has established a unified administrative management and operation mechanism of tobacco industry and formulates strict monopoly laws and rules, thus, tobacco production becomes regionalized, standardized and excellent from the original backwardness of varieties, scattered planting and low yield, the technology and equipment of part tobacco companies gradually get close to or reach the world advanced level, the structure of tobacco products has changed greatly, the quality is greatly improved, consumers' demand has been basically satisfied, and the taxation of tobacco industry has accumulated a huge amount of money for the country's economic construction and has made a significant contribution. 


\section{A. Active Control by Chinese Tobacco Industry Regulation}

The special characteristics of tobacco industry determines that the interests of tobacco growers will be damaged by the pursuit of corporate profit maximization in the process of production and operation, therefore, it will not well work to rely only on market forces, but to rely on regulation to control the number of tobacco enterprises and tobacco products and to safeguard the interests of tobacco growers and increase their income.

First, the government's participation is essential, which is determined by the public ownership system in China and the tobacco's characteristics of "addiction" and high profit tax. In case of being operated by enterprises only by market means, there will occur the following cases:

Companies are strong group with the goal of maximizing profits and tobacco growers are weak and dispersed group. The two groups belong to different interest entities, and their contradictions emerge in an endless stream, eventually leading to the failure of the mode. First of all, let's consider the companies' behavior to tobacco growers. If the companies are divided into good and bad, and if the good companies help growers to withstand market risks and adhere to the planned purchase under a sharp demand decline, but the bad companies transfer the market risk through depress market prices to reap higher profits. Assuming good and bad probability is $1 / 2$ and the earning return to supply bad companies is $R 3$ (R1 $>R 2>R 3$ ), the game matrix between the companies and tobacco growers is shown as follows:

Tobacco Growers

\begin{tabular}{|c|c|c|c|}
\cline { 2 - 4 } Good & & Supply & No Supply \\
\cline { 2 - 4 } Companies & Purchase & B1, R1 & -C, R2 \\
\cline { 2 - 4 } & No Purchase & 0,0 & 0, R2 \\
\cline { 2 - 4 } & &
\end{tabular}

Tobacco Growers

\begin{tabular}{c|r|c|c|}
\cline { 2 - 4 } \multicolumn{1}{c|}{ Bad } & Supply & No Supply \\
\cline { 2 - 4 } & Purchase & B2, R3 & -C, R2 \\
\cline { 2 - 4 } Companies & No Purchase & 0,0 & 0, R2 \\
\cline { 2 - 4 } & &
\end{tabular}

( $\mathrm{B} 1<\mathrm{B} 2, \mathrm{R} 1>\mathrm{R} 2>\mathrm{R} 3, \mathrm{C}$ is Operation cost)

Fig. 2. Game Matrix Diagram between Good Companies / Bad Companies and Tobacco Growers

Therefore, growers' expected return is only $1 / 2 \mathrm{R} 1+1 / 2 \mathrm{R} 3<\mathrm{R} 2$ (even the good companies can provide only slightly higher purchase price than the market price, but the bad companies will squeeze down price much lower than the market price), so growers are less willing to join this model. Due to the price fluctuation, the companies will take the form of contract to request growers to provide products or conceal the market price information (it is difficult to realize in the information times), and once the growers are controlled, the companies will make moral risk to lower price, which is determined by the maximized motivation of company's own interest. Without the government's support and protection, the growers are usually weak to struggle with the companies, thus only to expect a good company, but the fact always goes contrary.

Then, assuming that the companies are all good, but the tobacco growers are divided into good and bad (not providing products according to the contract). In such case, the moral hazard is generated again. Under the condition of bad tobacco growers, the companies cannot purchase the quantity of the products as they need and earns no profit or even loss, and finally, the companies go bankrupt, which damages the interests of good growers. Since the companies and the tobacco growers usually play the game in two stages (the contract is concluded and the companies first offers the order), the game tree between the two is shown as follows:

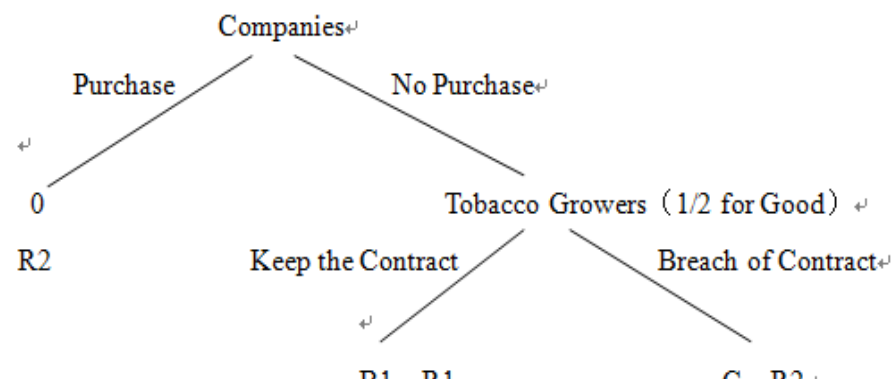

Fig. 3. Companies' Game with Good/Bad Tobacco Growers

If $1 / 2 \mathrm{~B}<1 / 2 \mathrm{C}$, the companies will not choose to purchase as per the reverse deduction. It is a better solution for the companies to buy corresponding number of products from the market and keep the debt in the tobacco growers' name if the tobacco growers would not like to sell products (tobacco) to the companies. The profits made by what they sell by themselves will be offset, or the government directly forces the growers to sell products to the companies as implemented. If no actions are made, the "lemon market" will be produced in which bad tobacco growers expels good ones, and this will eventually lead to the disintegration of this model.

The government plays the role of "Intermediary" and "Manager" in this process. The companies first act, and there is asymmetric information about the companies (there are good companies and bad ones), then the companies start to make decisions, and finally comes to the tobacco growers. As a result, the game tree is shown as follows (without consideration of government revenue):

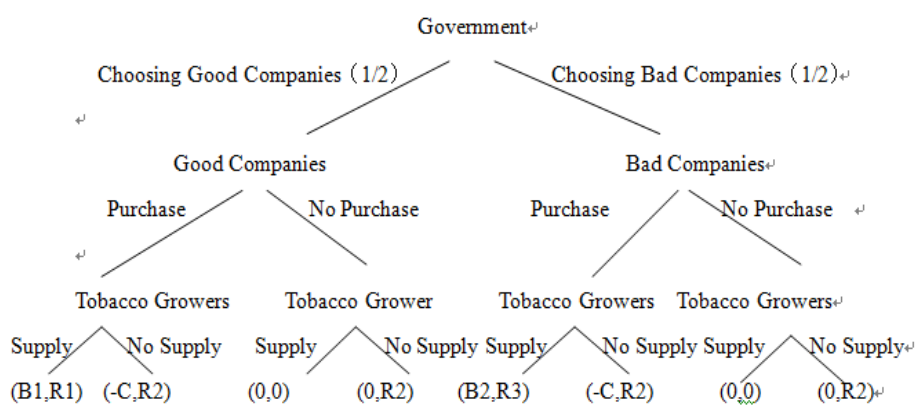

$(\mathrm{B} 1<\mathrm{B} 2, \mathrm{R} 1>\mathrm{R} 2$ ( Sales by Themselves) $>\mathrm{R} 3$ )

Fig. 4. Game Tree between the Companies and Tobacco Growers after the Government Involved 
At this point, the growers' earning by supply of tobacco is still $1 / 2 R 1+1 / 2 R 3$, but the earning is $1 / 2 R 2+1 / 2 R 2=R 2$ in case of not supplying, thus they will still not choose to supply. Therefore, the government should play the role to eliminate this uncertainty and to choose a company that is in line with the local development (a good company). This requires the local government to consider the long-term interests and the interests of the growers rather than blindly pursuing the political achievements and the local economic development. As described by Zhang Wuchang, every local government in China now becomes a pattern similar to the chairman or the manager and each area is similar to a large enterprise.

Therefore, the particularity of the tobacco industry in China has formed a "Three-in-One" model: the local government - tobacco enterprises - tobacco growers. In addition to the unified purchase (self-sale is illegal), a contract responsibility system of Companies + Growers + Local Government is constituted. In Aoki Masahiko's view, the entry and exit freedom should also be ensured, the companies should not be allowed to completely control tobacco growers, and government should place more of the policy support to tobacco growers.

\section{B. Adverse Effects of Chinese Tobacco Industry Regulation}

The regulation measures released by China with regard to planting and purchasing have effectively corrected the tobacco industry, but it has caused a great impact on the income of growers, especially on the tobacco growers, which effectually caused such a paradox of policy as planting area of tobacco has been increased rather than decreased. The phenomenon cannot be attributed to the poor control of local government, but should be the result of egoism and rational factors. It is well known that tobacco production will bring huge tax revenue to local finance and bring higher profits to tobacco growers than ordinary crops. Under the established conditions of growing area, there will be the following game in all levels of counties: (note: $\mathrm{P}$ represents the tax revenue earned by local governments, and $\mathrm{L}$ represents legal benefit earned by tobacco growers' sales, and $\mathrm{N}$ is a real number greater than 0 .)

Tobacco Growers (Single)

\begin{tabular}{|c|c|c|c|}
\hline & & Excess planting & No Excess planting \\
\hline \multirow{3}{*}{ Local Government } & Agree & $(\mathrm{P}, \mathrm{L})$ & $\begin{array}{l}(\mathrm{P}, 0) \\
\text { (PS: others will } \\
\text { excess planting) }\end{array}$ \\
\hline & + & & \\
\hline & Opposition & $\begin{array}{c}(0, \mathrm{~nL}) \\
\text { (PS: Black market) }\end{array}$ & $(0,0)$ \\
\hline
\end{tabular}

Fig. 5. Game Matrix Diagram between a Single Tobacco Grower and a Local Government

In this game, since the benefit by planting must be higher than the tax (otherwise there will be no planting motivation), $\mathrm{L}>\mathrm{P}(\mathrm{P} \geqslant 0, \mathrm{~L} \geqslant 0)$. It is clear that the best decision made by the local government and the growers are excess planting ((agreeing excess planting, excess planting) strategic set), but the country expects that the optimal action is a combination of (against excess planting, no excess planting) strategy set, which resulted in contradict result to the policy.

\section{COnClusion and Policy Recommendations}

The long existing regulation for Chinese tobacco industry and the national monopoly, in the view of free market school, will bring bad influence on the market regulation. In this paper, the author argues that considering the tobacco's characteristics of high taxes and addiction, China must carry out macrocontrol in order to inhibit increase of tobacco planting area dramatically and control the quantity and quality of tobacco, thus maintains a stable and harmonious society. However, tobacco industry cannot be fully regulated, because a series of problems such as waste of resources, unfairness, rent-seeking and other issues shall be generated lacking of the basic role of market,. Therefore, the author believes that combing "Invisible Hand" and "Visible Hand" by amendment and improvement of national regulation policy could promote the development of tobacco industry. It can be perfected from the following aspects: (1) Making efforts to eliminate local protectionism. The root of local protectionism is tax dependence, which can be eliminated only through the reform of tobacco tax. First, the consumption tax should be levied from production link to consumption link, i.e. taxes should be levied on the sales of cigarette and then tax sharing system shall be reformed. Different tax refund bases should be set up and fixed in different places, so that they will not be related to increase or decrease of tobacco tax. In addition, local protectionism comes from local officials' wrong view of achievements. It is necessary to reform evaluation system and strengthen trainings, which makes the officials with a long-term vision and global interests and breaks the provincial barriers to open the local market in order to eliminate local protectionism fundamentally. (2) Weaken the binding force of regulation policy gradually complying with international trend. Due to tobacco's characteristics of addiction and high taxes, tobacco monopoly system has been implemented in most countries in early times except the United States and some other countries. Marketization has become the theme of present economic development, so the national macro-control policies represented by "Double Control" should be gradually weakened, and guidance and standardization rather than administrative intervention should be focused on. Since the combination of "Invisible Hand" and "Visible Hand" is targeting the role of market, the national regulation should not become the domination so as not to curb the development of tobacco industry.

\section{REFERENCES}

[1] Cutler D. "The Economic Impacts of the Tobacco Settlement". Journal of Analysis and Management, 2001, No.1, pp.l-19.

[2] Tao Ming. Chinese Tobacco Industry under the Monopoly System: Theory, Problem and Institutional Reform [M]. Xue Lin Press, 2005 (10).

[3] Robert Gibbons. The Basis of Game Theory [M]. Chinese Social Science Press, 1999 (03). 
[4] Luo Meijuan. Analysis of the Influence of Government Regulation on the Behavior of Chinese Tobacco Enterprises and Market Structure [J]. Ideological Front. 2004 (06): 88-91
[5] Shanghai University of Finance and Economics Research Group. Chinese Industrial Development Report of 2006: Manufacturing Industry's Market Structure, Behavior and Performance [M]. Shanghai University of Finance and Economics Press, 2006 (08). 